\title{
Contribution of biomarkers to personalized medicine
}

\author{
Daniel F Hayes*
}

The theme of the 2009 Annual Meeting of the American Society of Clinical Oncology (ASCO), presided by Dr Richard L Schilsky, was 'Personalizing Cancer Care' [1]. Dr Schilsky noted that 'as oncologists, our focus has always been, and must remain, treating the patient, not the disease. We must each acquire the skills and make the commitment to do so in an optimal way'.

In an era of increasingly common therapies that are directed towards a specific target, Dr. Schilsky's words ring true, but also raise the question, 'what skills and what commitment?' Personalized cancer care requires a thorough knowledge and understanding of evidencebased medicine, particularly as it applies to the judicious use of biomarkers to carefully select patients most likely to benefit and least likely to suffer toxicities from our therapies. Indeed, the remarkable reduction in mortality from breast cancer over the past four decades raises a second question that, indeed, challenges the concept of personalized care: 'Should we treat all patients with every new therapy in order to maximize this reduction?' Unless a patient is willing to accept any toxicity for the smallest gain, and society is willing to pay for it, the obvious answer is 'no'. Sadly, with only a few exceptions, the field has fallen far short of providing the sort of data that are required to reliably identify those patients who are so unlikely to benefit that they would forego therapy. In fact, the ASCO Tumor Marker Guidelines Committee has recommended only five markers that might be used to make clinical decisions regarding patients with newly diagnosed breast cancer: estrogen receptor (ER) and progesterone receptor (to select patients for endocrine therapy), human epidermal growth factor receptor 2 (HER2; to select patients for anti-HER2 therapies, in particular trastuzumab and labatinib), and urokinasetype plasminogen activator (uPA)/plasminogen activator inhibitor-1 (PAI1) and/or the 21 gene Recurrence Score to identify patients with node negative, ER-positive

*Correspondence: hayesdf@umich.edu

Breast Oncology Program, University of Michigan Comprehensive Cancer Center, 1500 E. Medical Center Drive, Ann Arbor, MI 48109, USA breast cancer whose prognosis is so good that chemotherapy is very unlikely to be of benefit [2].

Why are these recommendations so conservative? The ASCO Tumor Marker Guidelines Committee and others have generated proposals to provide a framework in which the relative value of a tumor marker might be evaluated objectively. In this regard, it is important to determine the intended use of the marker, such as determining prognosis or predicting that a generic class of treatments (for example, endocrine or chemotherapy) or specific agents (for example, anti-NERC therapies) will work against the particular tumor. Secondly, it is essential that the clinician be able to estimate the relative magnitude in the difference of outcomes for patients who are 'positive' versus those who are 'negative' for the marker, and whether that magnitude is sufficient to guide treatment differently than if the data were not available [3]. Importantly, it is critical that this estimate be accurate and reliable. The Guidelines Committee jointly published a framework, designated the Tumor Marker Utility Grading System, in which they first proposed a hierarchy of levels of evidence that might be used to determine if available data support the use of a marker of not [4]. This level of evidence scale has recently been revised to distinguish data generated from prospective clinical trials in which the marker is the primary objective of the study $[5,6]$ from those in which archived specimens are used [7]. Many of these concepts have recently been codified by the Evaluation of Genomic Applications in Practice and Prevention (EGAPP) Initiative [8], in which tumor marker evaluation was placed into three semantic states: analytical validity - the importance of a stable, accurate, and reproducible assay for the marker; clinical validity evidence that the marker does, indeed, separate two subgroups of patients with different outcomes within a large population; and clinical utility - evidence that use of the marker improves outcomes compared to not using it.

It is absolutely essential that, before a marker be ordered or used to make clinical decisions, analytical validity is established. Doing so takes enormous effort and conscientious care to 'get it right'. Recently, ASCO and the College of American Pathologists (CAP) have partnered to convene two expert panels to review not 
only the indications but also the techniques for performing HER2 [9] and ER [10] assays, the two most critical biomarkers in breast cancer, if not all of oncology. Incredibly, these panels found large variation in the standardization and quality of the assays for these two markers, and they established proficiency testing. Clinicians and patients are strongly urged to be certain that these markers are evaluated in an accredited laboratory that participates in the CAP, or similar, proficiency testing program.

Assuming analytical validity is established, why do we not have more markers with high levels of evidence to support clinical utility? A cursory review reveals more than 1,000 papers published during the past decade in the English literature regarding breast cancer and tumor markers, biomarkers, or prognostic or predictive factors. However, most, if not all of these provide only clinical validity, with little or no effort to produce high level evidence for clinical utility, principally because to do so requires careful planning, hard work, extensive time, and substantial cost. In general, there is a very poor valuation for tumor marker use, research, funding, reimbursement, or evaluation by our society and profession. These issues have established a 'vicious cycle' in which marker research is under-funded and lacks the rigor of basic laboratory or therapeutic clinical research, and therefore marker use is based on low level data.

Clinicians must recognize that a bad tumor marker is every bit as harmful as a bad drug. It will take fundamental changes in all aspects of marker research and clinical use to break this cycle. In fact, several initiatives have begun to do so. In addition to the definitions and levels of evidence scales discussed above, McShane and colleagues [11] published reporting recommendations for tumor marker prognostic studies (REMARK criteria), which have been endorsed, although not as widely adopted as hoped, by many journal editors. Furthermore, the National Cancer Institute of the United States established a new, separate study section (the Cancer Biomarkers Study Section) specifically to provide high levels of expertise in peer review of grants focused on tumor marker research. The National Cancer Institute has also established a unique Office of Biorepository and BioSpecimen Research with the mission of developing a biorepository infrastructure that promotes resource sharing and team science in order to facilitate multiinstitutional high throughput genomic and proteomic studies'.

One hopes that these and future initiatives will raise the level of tumor marker research to that of therapeutics, so that clinicians, and patients, can reliably apply the long-sought concepts of 'personalized cancer care'.

\section{Abbreviations}

ASCO, American Society of Clinical Oncology; CAP, College of American Pathologists; ER, estrogen receptor; HER, human epidermal growth factor receptor.

\section{Competing interests}

The author declares that they have no competing interests.

\section{Acknowledgements}

This article has been published as part of Breast Cancer Research Volume 12 Supplement 4, 2010: Controversies in Breast Cancer 2010. The full contents of the supplement are available online at http://breast-cancer-research.com/ supplements/12/S4

Published: 20 December 2010

\section{References}

1. Schilsky RL: Personalizing Cancer Care: American Society of Clinical Oncology Presidential Address 2009 [http://jco.ascopubs.org/ content/27/23/3725.full]

2. Harris L, Fritsche H, Mennel R, Norton L, Ravdin P, Taube S, Somerfield MR, Hayes DF, Bast RC Jr; American Society of Clinical Oncology: American Society of Clinical Oncology 2007 update of recommendations for the use of tumor markers in breast cancer. J Clin Oncol 2007, 25:5287-52312.

3. Henry NL, Hayes DF: Uses and abuses of tumor markers in the diagnosis, monitoring, and treatment of primary and metastatic breast cancer. Oncologist 2006, 11:541-552.

4. Hayes DF, Bast RC, Desch CE, Fritsche H Jr, Kemeny NE, Jessup JM, Locker GY, Macdonald JS, Mennel RG, Norton L, Ravdin P, Taube S, Winn RJ: Tumor marker utility grading system: a framework to evaluate clinical utility of tumor markers. J Natl Cancer Inst 1996, 88:1456-1466.

5. Sargent DJ, Conley BA, Allegra C, Collette L: Clinical trial designs for predictive marker validation in cancer treatment trials. J Clin Oncol 2005, 23:2020-2027.

6. Freidlin B, MCShane LM, Korn EL: Randomized clinical trials with biomarkers: design issues. J Natl Cancer Inst 2010, 102:152-160.

7. Simon RM, Paik S, Hayes DF: Use of archived specimens in evaluation of prognostic and predictive biomarkers. J Natl Cancer Inst 2009, 101:1446-1452.

8. Teutsch SM, Bradley LA, Palomaki GE, Haddow JE, Piper M, Calonge N, Dotson WD, Douglas MP, Berg AO; EGAPP Working Group: The Evaluation of Genomic Applications in Practice and Prevention (EGAPP) Initiative: methods of the EGAPP Working Group. Genet Med 2009, 11:3-14.

9. Wolff AC, Hammond ME, Schwartz JN, Hagerty KL, Allred DC, Cote RJ, Dowsett M, Fitzgibbons PL, Hanna WM, Langer A, McShane LM, Paik S, Pegram MD, Perez EA, Press MF, Rhodes A, Sturgeon C, Taube SE, Tubbs R, Vance GH, van de Vijver M, Wheeler TM, Hayes DF; American Society of Clinical Oncology; College of American Pathologists: American Society of Clinical Oncology/College of American Pathologists guideline recommendations for human epidermal growth factor receptor 2 testing in breast cancer. $J$ Clin Oncol 2007, 25:118-145.

10. Hammond ME, Hayes DF, Dowsett M, Allred DC, Hagerty KL, Badve S, Fitzgibbons PL, Francis G, Goldstein NS, Hayes M, Hicks DG, Lester S, Love R, Mangu PB, McShane L, Miller K, Osborne CK, Paik S, Perlmutter J, Rhodes A, Sasano H, Schwartz JN, Sweep FC, Taube S, Torlakovic EE, Valenstein P, Viale G, Visscher D, Wheeler T, Williams RB, et al:: American Society of Clinical Oncology/College of American Pathologists guideline recommendations for immunohistochemical testing of estrogen and progesterone receptors in breast cancer. J Clin Oncol 2010, 28:2784-2795.

11. McShane LM, Altman DG, Sauerbrei W, Taube SE, Gion M, Clark GM; Statistics Subcommittee of the NCI-EORTC Working Group on Cancer Diagnostics: Reporting recommendations for tumor marker prognostic studies (REMARK). J Nat/ Cancer Inst 2005, 97:1180-1184.

doi:10.1186/bcr2732

Cite this article as: Hayes DF: Contribution of biomarkers to personalized medicine. Breast Cancer Research 2010, 12(Suppl 4):S3. 